\title{
Assessment of Kala-Azar in Dumka District of Jharkhand, India
}

\author{
Vidushi Topno $^{1}$, Vikas Oraon ${ }^{2}$ \\ ${ }^{1}$ Tutor, Department of Microbiology, Phulo Jhano Medical College, Dumka. \\ ${ }^{2}$ Assistant. Professor, Department of Microbiology, Phulo Jhano Medical College, Dumka \\ Corresponding Author: Vikas Oraon
}

DOI: https://doi.org/10.52403/ijrr.20220136

\begin{abstract}
Kala-azar is a vector-borne disease and a serious public health problem in India. Highly affected states in India are Bihar, Jharkhand, West Bengal and Uttar Pradesh. In 2010, 14.87\% cases were contributed from Jharkhand. The study was done to know the trend of disease in five year duration (2016-2020) in Dumka District, Jharkhand.

Method - This was a cross-sectional study. It was executed in 10 Blocks of District Dumka Jharkhand. Convenience sampling technique was used in this study. Data analysis was done from the line-list of District Vector Borne Disease Control Office, Dumka.

Result - During the 5 year study period there was annual reduction in the trend of visceral leishmaniasis. Male cases were more predominant. Age group >21 years were maximum affected. VL had affected all the 10 Blocks. PKDL cases were seen maximum in Blocks like Ramgarh, Dumka Sada, Kathikund and Gopikander.
\end{abstract}

Conclusion- Annual reduction of incidence of Kala-azar reveals that the current Kala-azar elimination strategy is highly effective and elimination of disease from endemic blocks is possible. Further improvement in treatment, elimination strategies and accessibility of primary health care services in endemic rural areas can gear up to get over last-mile obstacles.

Keywords- Visceral Leishmaniasis, Indoor Residual Spraying, Post Kala-azar Dermal Leishmaniasis, Kala-azar.

\section{INTRODUCTION}

Kala-azar or visceral leishmaniasis (VL) means black fever in Hindi. It is a vector borne disease causing serious health problem. According to World Health Organisation it is one of the fatal diseases among seven most important tropical diseases. ${ }^{1,2}$ In less developed countries kalaazar is more endemic. About $67 \%$ of global VL disease reside in India, Nepal and Bangladesh. ${ }^{3}$ Worldwide in 88 countries the disease is endemic, infecting around 2 million people each year., ${ }^{4,5}$ Numerous outbreaks of Kala-azar has been seen in India. $^{6} 7,60,432$ Kala-azar cases were reported during year 1987 to 2011 in India.

India, since 2012 has made progress in eradication of the disease but VL is stable in four middle-eastern states including Jharkhand. During the period 2000 to 2011 Jharkhand state had 44,180 reported cases. During 2006, 7,508 cases were recorded which was highest recorded number in Jharkhand. There was sharp decline till 2009 followed by increase till 2011 . $^{7}$

kala azar is transmitted by bite of female phlebotomine sand flies. Its symptoms are fever, weight loss, splenomegaly, hepatomegaly, skin darkening, and anemia. ${ }^{8,9}$ Major elements associated VL are poverty, poor sanitary conditions and malnutrition. ${ }^{10,11}$ Malnourished people due to weakened immune system are at higher risk of developing VL. ${ }^{12}$ It closely related to socioeconomic, environmental and climatic 
factors. Rainfall, temperature and vegetation coverage are the major determining factor for the harbour of visceral leishmaniasis. 13,14

It became compulsory in India to report VL under NVBDCP from 2005. ${ }^{15}$ To eliminate VL as a public health problem by 2015, Bangladesh, India and Nepal developed framework for elimination. Annual incidence of $<1$ case per 10,000 people of VL at the sub-district/block level is defined as Elimination. ${ }^{16,17}$

Dumka District is a tribal region also known as Santhal Pargana region. It is a sub-capital of Jharkhand state. Kala-azar cases are very frequently found in this region. Dumka is surrounded by forests, hills and rivers. It is covered with 120763 acres of forest. Climate is humid subtropical with wet summers and mild winters. Villages housing material consists of mud wall and thatchs. ${ }^{18}$ All these conditions goes in favour of shelter for parasite. The study aims to know the disease trend by assessing 5 year data and to know the effect of Elimination programme in Dumka District.

\section{MATERIAL AND METHODS}

The study was carried out in Phulo Jhano Medical College, Dumka, Jharkhand, in Department of Microbiology. A community based cross-sectional study was done in the population belonging to Dumka District. The study period was of five year duration. Present study was conducted in 10
Blocks of District Dumka, Jharkhand, India. 10 Blocks under District Dumka are Dumka Sadar, Jama, Shikaripara, Raneshwer, Masalia, Kathikund, Gopikander, Ramgarh, Jarmundi and Saraiyahat.

The epidemiological VL case database was generated for 2016 to 2020 . The annual line-list of the total VL and postKala-azar dermal leishmaniasis (PKDL) patients treated during the year were obtained from the District Vector Borne Disease Control Office (DVBDCO), Dumka, Jharkhand.

To assess the situation of VL and PKDL in Dumka District variables like age, sex, weight, date of onset of symptoms, treatment history, date of treatment completion were used. In Excel spread sheet using Microsoft Office all data were stored. Graph preparations (bar and line graphs) and statistical analysis were performed using Excel and SPSS 20.0. Depending upon the data proper statistical parametric and non-parametric tests were applied.

\section{RESULT}

Trend of annual reduction was seen in VL during 5 year study period. In the year 2016 total cases of kala-azar were 489 cases, in 2017 there were 377 cases, 2018 consisted of 198 cases, in 2019 there were 157 cases and 2020 consisted of 133 cases. A declining trend in incidence of kala-azar was seen from 2016 to 2020 .

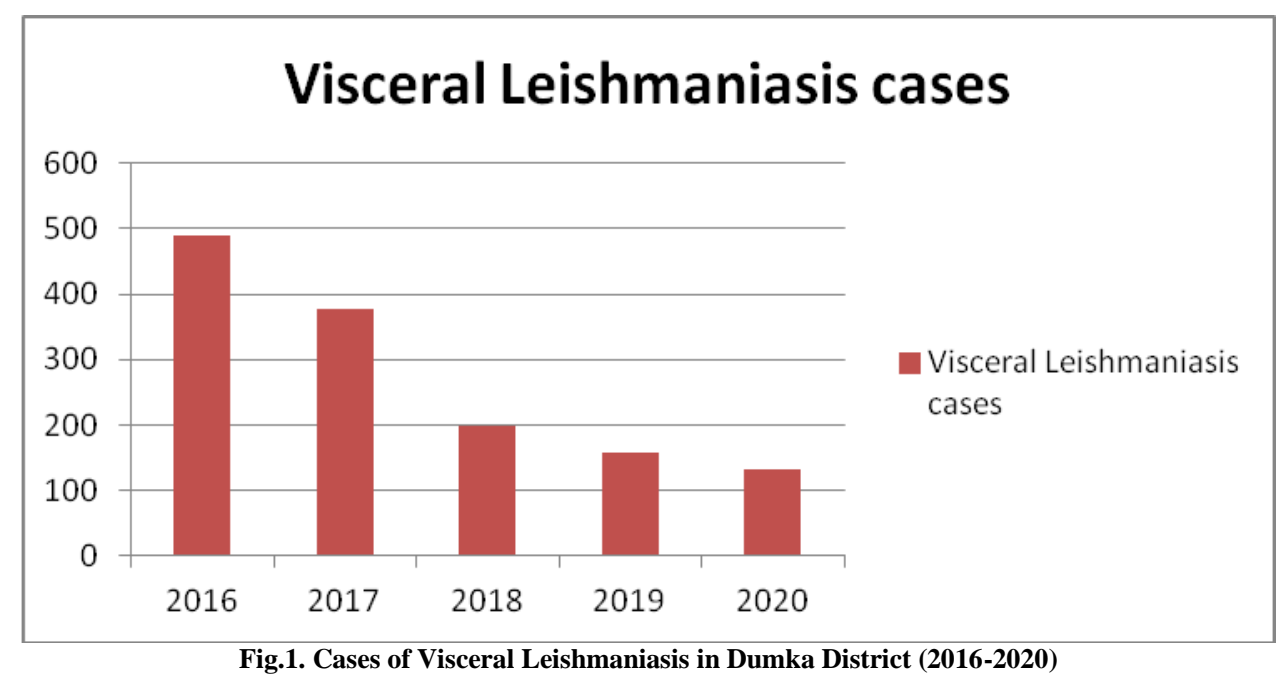

Fig.1. Cases of Visceral Leishmaniasis in Dumka District (2016-2020) 
Total PKDL cases in the year 2016 were 136, in 2017 cases were 208, in 2018 there were 45 cases, in 2019 were 25 cases and in 2020 the cases were 41 . There was increase in number of cases from the year 2016 to 2017 and then there was decline in cases till 2019 , but again there was rise in number of cases in 2020.

In the year 2016 maximum number of cases were seen in Kathikund block (21.60\%), followed by Jama block(21.2\%). In 2017 maximum number of cases were seen in Dumka sadar block(21.8\%) followed by Ramgarh $(21 \%)$. Maximum number of cases were seen in Jama (27.10\%) in 2018 followed by Ramgarh (26\%). In the year 2019 maximum number of cases were seen in Jama $(32.10 \%)$ followed by Dumka (17\%). In 2020 maximum cases were seen in Dumka $(25 \%)$ followed by Jama (19.70\%). Cases of VL in Dumka District is mostly found in blocks like Jama, Dumka, Ramgarh and Kathikund.

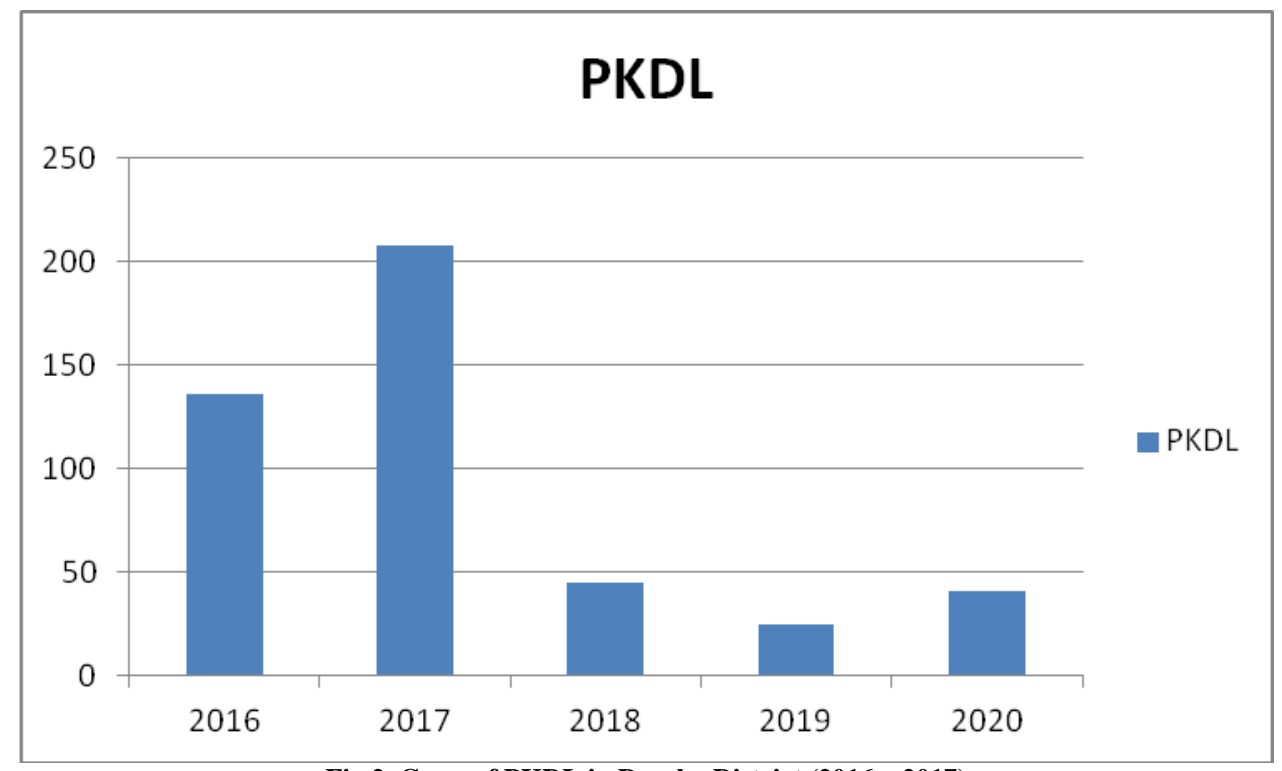

Fig.2. Cases of PKDL in Dumka District (2016 - 2017)

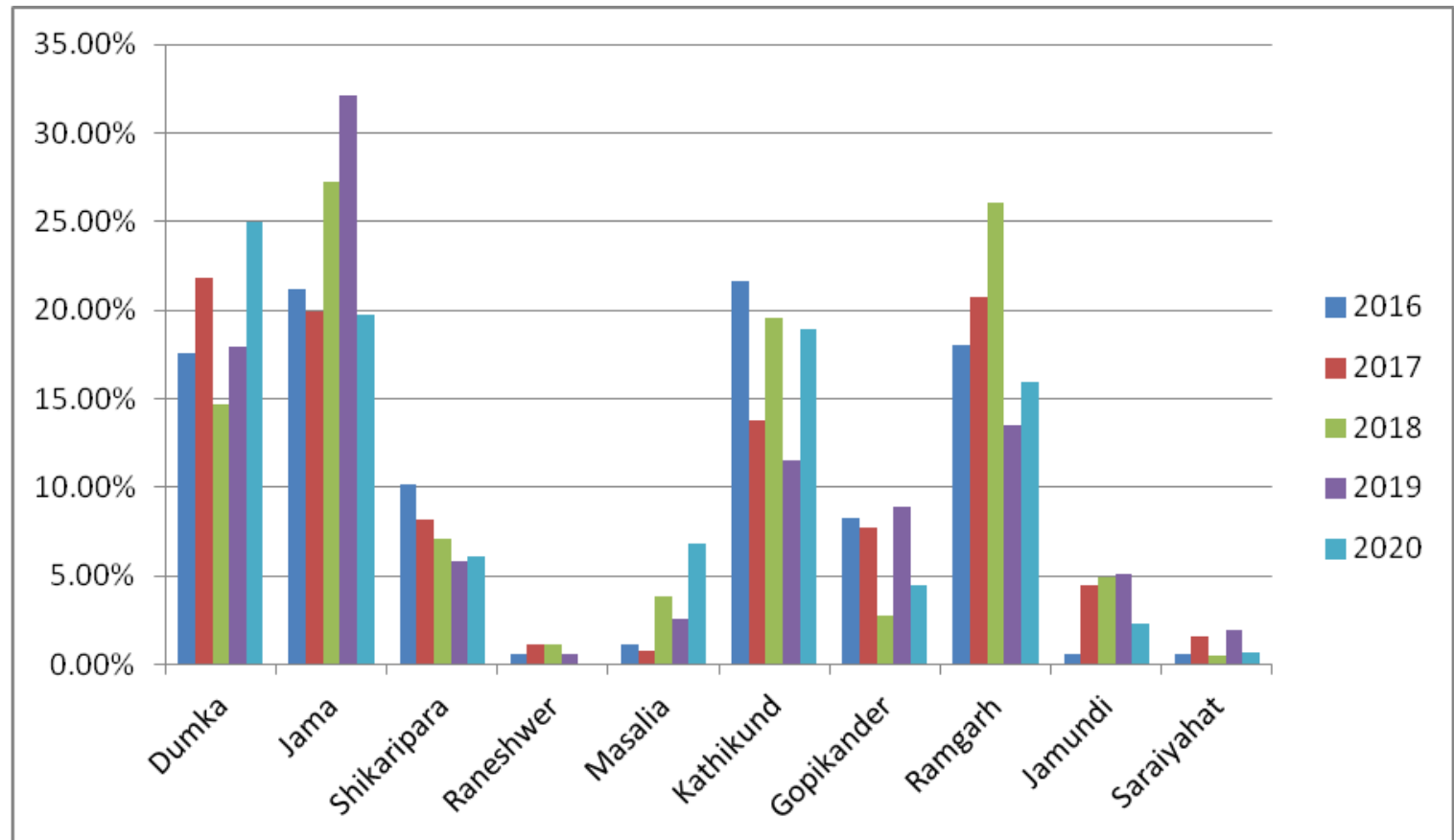

Fig.3. Percentage of VL cases in 10 Blocks of Dumka District (2016 - 2020) 


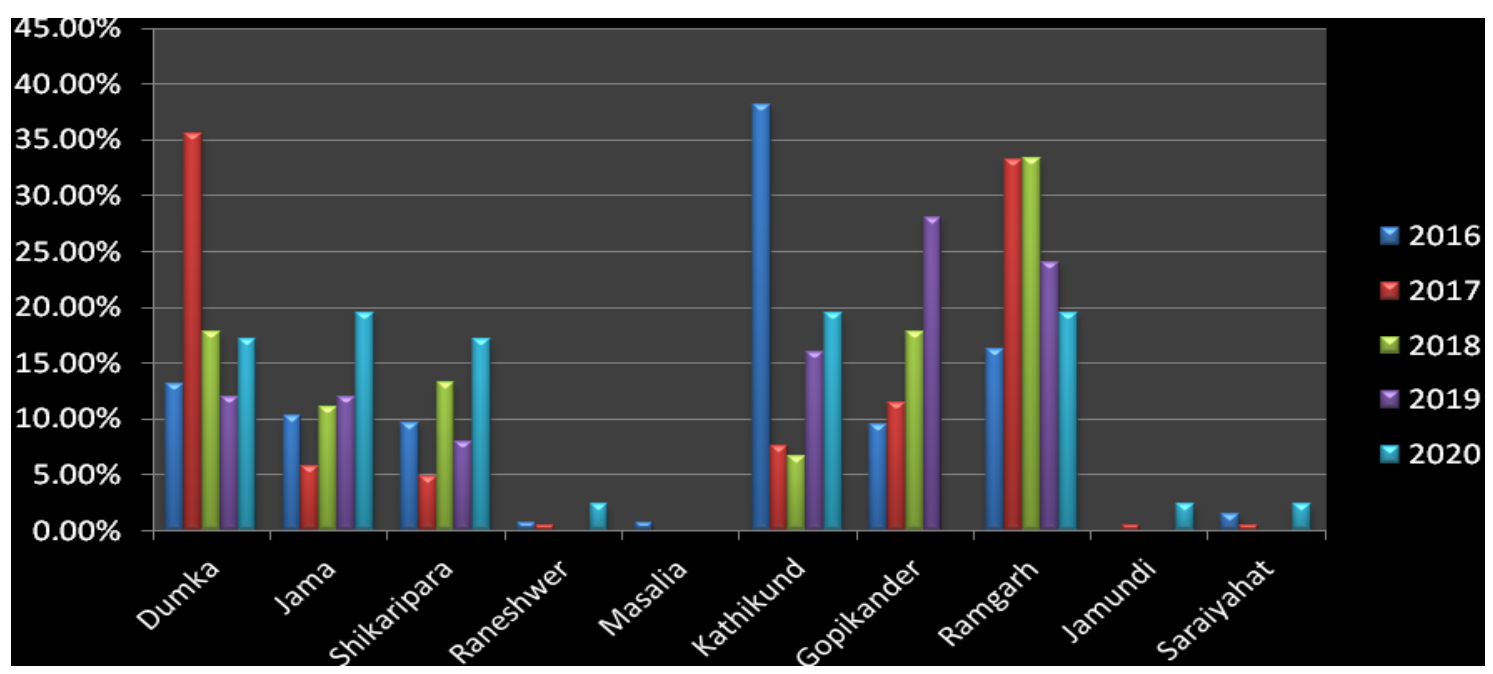

Fig.4. Percentage of PKDL cases in 10 Blocks of Dumka District (2016 - 2020)

In the year 2016 maximum number of PKDL cases were seen in Kathikund (38.20\%) followed by Ramgarh (16.2\%). In 2017 maximum cases were seen in Dumka sadar block $(35.60 \%)$ followed by Ramgarh (33.20\%). In 2018 maximum cases were seen in Ramgarh (33.30\%) followed by Dumka sadar block $(17.80 \%)$ and Gopikander (17.8\%). In 2019 maximum number of cases found in Gopikander (28.0\%) and Ramgarh (24.0\%). In 2020 maximum number of cases were seen in Ramgarh (19.50\%), Kathikund (19.50\%) and Jama (19.50\%). Maximum number of cases were seen Ramgarh, Dumka, Kathikund and Gopikander.

In 5 years study duration (20162020), VL was predominant in males. In
2016 male cases were $59.10 \%$, in 2017 it was $56 \%$, in 2018 it was $65.20 \%$, in 2019 it was $73.2 \%$ and in 2020 it was $62.20 \%$. Female cases were $40.90 \%$ in 2016, in 2017 cases were $44 \%$, in 2018 it was $34.8 \%$, in 2019 cases were $26.80 \%$ and in 2020 the cases were $37.80 \%$.

In 2016, PKDL cases were $50.70 \%$ male and $49.30 \%$ in female, in 2017 male cases were $54.4 \%$ and female cases were $45.65 \%$, in 2018 male cases were $40 \%$ and female cases were $60 \%$, in 2019 males cases were $60 \%$ and female cases were $40 \%$ and in 2020 male cases were $58.70 \%$ and female cases were $41.30 \%$. Male cases were predominant in the year 2016, 2017, 2019 and 2020 but in 2018 female cases were predominant $(60 \%)$.

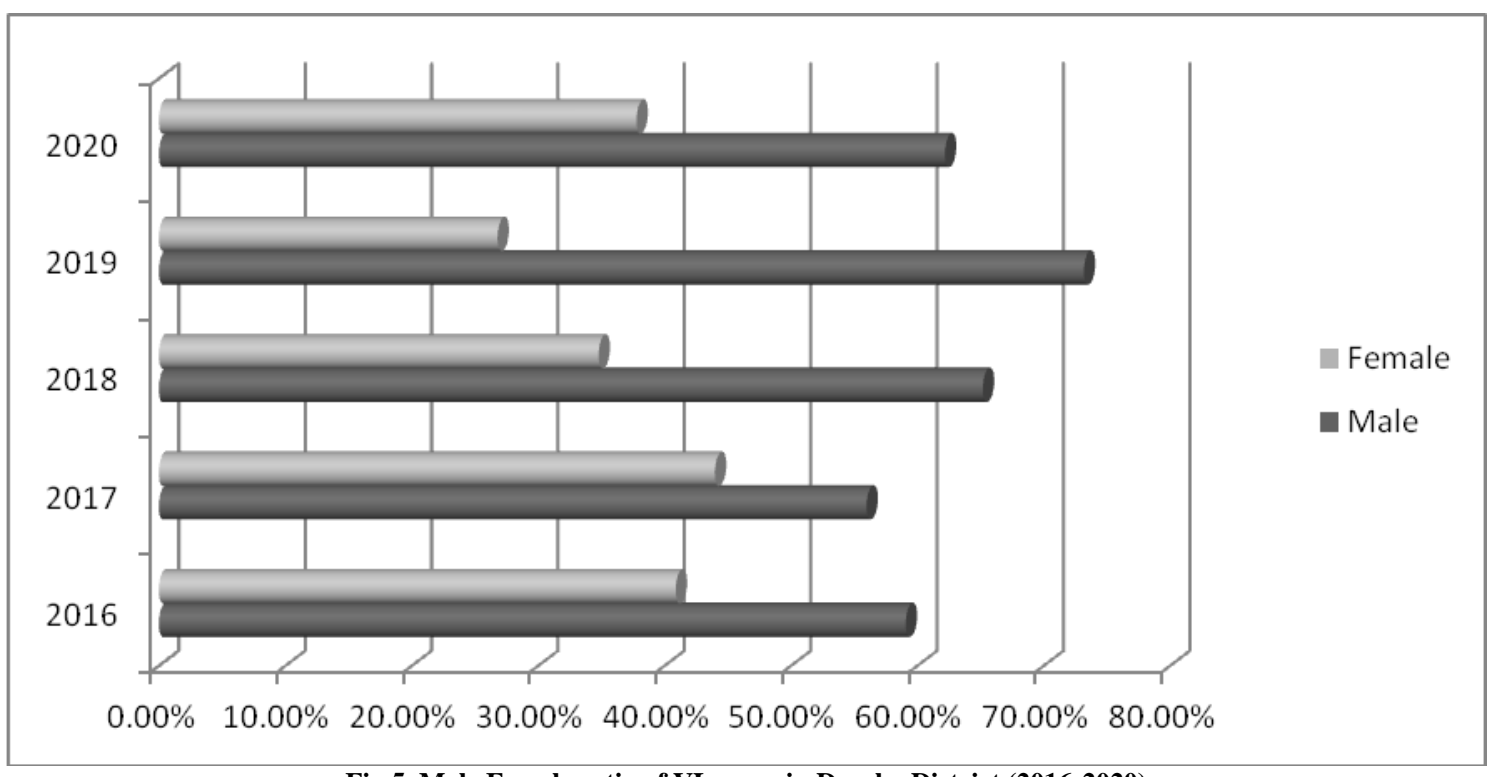

Fig.5. Male Female ratio of VL cases in Dumka District (2016-2020) 


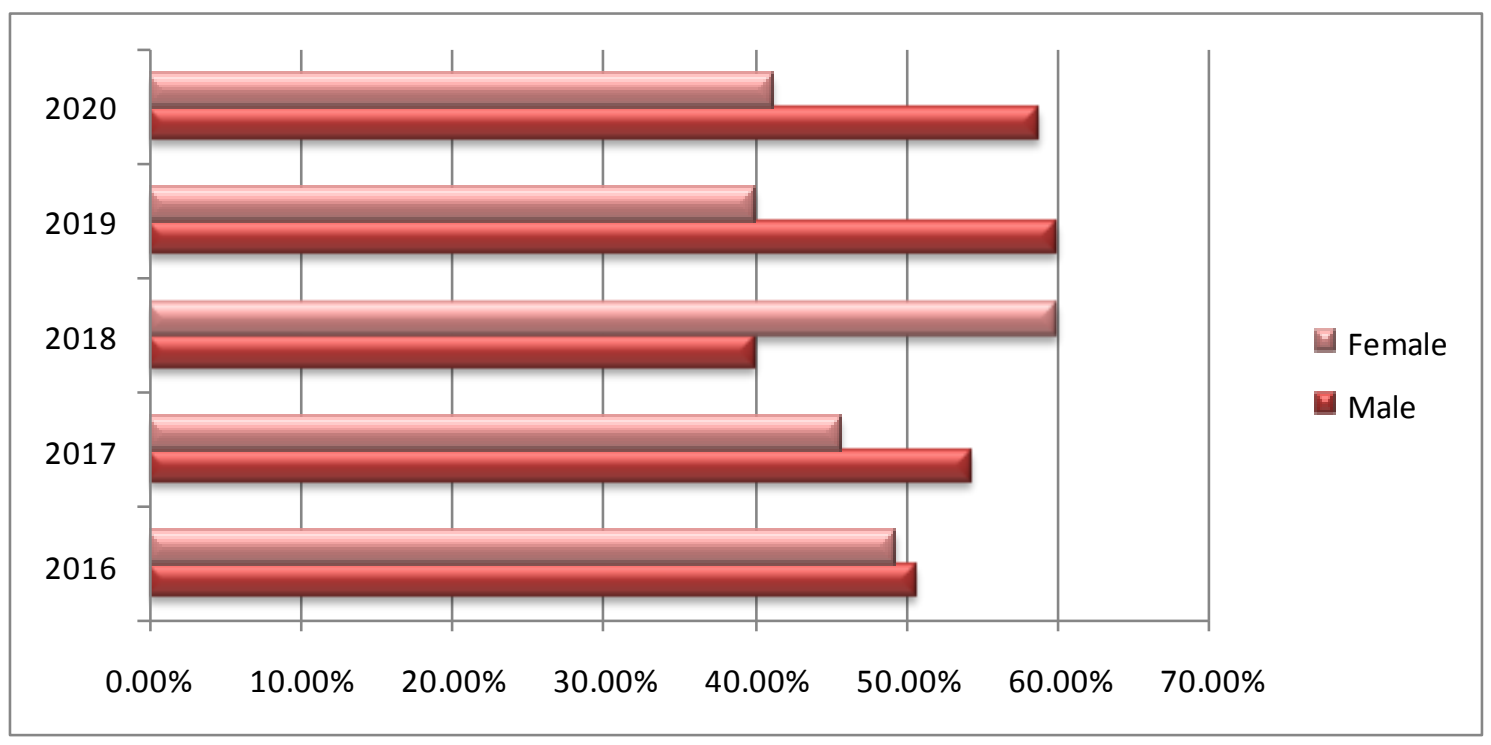

Fig.6. Male Female ratio of PKDL cases in Dumka District (2016-2020)

Maximum number of VL cases were above 21 years of age, $64.3 \%$ in 2016, $43.5 \%$ in $2017,55.5 \%$ cases in $2018,67.5 \%$ cases in 2019 and $75 \%$ cases in 2020 .

VL cases were seen in all 10 blocks of Dumka in the year 2016, 2017, 2018, 2019. In the year 2020 the disease was found in all blocks except in Raneshwer block. PKDL cases were seen in almost all blocks but in Raneshwer in the year 2018 and 2019 no case of PKDL was seen. In Masalia block only 1 PKDL case was seen in 2016. In Jamundi 1 case was seen in 2017 and 1 case in 2020. In Saraiyahat block 2 cases were seen in 2016, 1 case in 2017 and 1 in 2020. In the remaining blocks PKDL cases were seen in time period of 20162020.

\section{DISCUSSION}

The current study indicated Annual reduction of new VL cases in 5 years study period (2016-2020) in Dumka District, Jharkhand. These data revealed that more cases of VL were seen in males. In case of PKDL also more number of cases were seen in males but it was only in the year 2018 where female cases were more predominant. Male predominance in VL cases is also seen in previous studies in India. Higher incidence of cases in males is thought to be a result of clothing habits. ${ }^{19,20}$ In a sleeping condition survey, they discovered that men mostly sleep in traditional cloths like lungi, dhoti or towel. Present study supports the findings by Kumar and others. ${ }^{19}$ Kumar and others pointed out in sleeping condition survey that men's upper bodies are exposed due to traditional wear like lungi, dhoti, towel etc thus exposing more portion of body for the sand flies bite. These data also indicated that individuals above 21 years accounted for highest percentage of cases. Similar result was seen in work of Ranjan and others ${ }^{21}$, Perry and others. ${ }^{22}$

Present study showed that cases of VL were present in all the 10 blocks of Dumka district. Thus, proximity to another case is cogent risk factor in all the blocks. Strong association between rate of infection and vicinity to another case is observed. This association was also found in Bern and others. ${ }^{8}$ They suggest this association as a result of genetics affecting the progression of L.donovani among members of effected households. In another study, Bern and others found nutritional influences in household suffering from malnutrition. Malnutrition is a likely cause of lowered immune system and a high risk factor for developing disease. Bern and others found individuals with lower meat intake had lower immunity with higher risk of developing disease. ${ }^{23}$

Among poor $\mathrm{VL}$ is a predominant disease. Evidence shows that housing 
material, malnutrition and poor sanitary condition are the risk factor of VL. 10,24,23 Increased risk of VL was seen to be associated with use of mud and thatch as housing material. For parasite transmission asymptomatic individual can act as a reservoir. In a study of Topno and others neighbours of VL cases were seropositive (13\%), without any symptoms. ${ }^{25,26}$

Current governmental control method of spraying IRS was highly effective in reducing Kala-azar cases. In Northern Bihar, India IRS spraying as a control method has been highly effective nearly eliminating Kala-azar ${ }^{27,28}$.

\section{CONCLUSION}

Annual reduction of Kala-azar incidence indicates that control strategy of Kala-azar is effective in limiting in the occurrence of new cases. IRS (Indoor Residual Spraying) remains the backbone of VL vector control with improved coverage across all targeted villages. The strategy also helped to eradicate different types of human reservoirs of L.donovani among unnoticed pockets across villages. Early detection and complete treatment of cases is an important factor for successful control. Consistent surveillance with evaluation of disease is needed. A good supervision and monitoring of programme management will resolve remaining challenges in elimination of Kala-azar.

\section{Acknowledgement: None}

\section{Conflict of Interest: None}

\section{Source of Funding: None}

Ethical Approval: Approved

\section{REFERENCES}

1. Vargas-Martínez F, Torres-Guerrero E, Quintanilla-Cedillo MR, et al.: Leishmaniasis en México. Academia Mexicana de Dermatología, Colegio de Dermatólogos de Yucatán A. C., Fundación Mexicana para la Dermatología,Universidad Autónoma de Campeche y Secretaría de Salud, México. 2013.
2. Andrade-Narváez FJ, Vargas-González A, Canto-Lara SB, et al:: Clinical picture of cutaneous leishmaniases due to Leishmania (Leishmania) mexicana in thelYucatan peninsula, Mexico. Mem Inst Oswaldo Cruz. 2001; 96(2): 163-7.

3. P. J. Hotez, J. H. F. Remme, P. Buss, G. George, C. Morel, and J.G. Breman, "Combating tropical infectious diseases: report of the disease control priorities in developing countries project,"Clinical Infectious Diseases, vol. 38 , no. 6, pp. 871878, 2004.

4. Croft SL, Vivas L, Brooker S. Recent advances in research and control of malaria, leishmaniasis, trypanosomiasis and schistosomiasis. East Mediterr Health J. 2003 Jul;9(4):518-33. PMID: 15748049.

5. P. Desjuex, "Leishmaniasis: current situation and new perspectives," Comparative Immunology, Microbiology and Infectious Diseases, vol. 27, no. 5, pp. 305-318, 2004.

6. C. P.Thakur, "Treatment of kala-azar in India," National Medical Journal of India, vol. 5, no. 5, pp. 203-205, 1992.

7. Kumar V, Mandal R, Das S, Kesari S,Dinesh DS, Pandey K, et al. (2020) Kalaazar elimination in a highly-endemic district of Bihar, India: A success story. PLoS Negl Trop Dis 14(5):e0008254. https://doi.org/10.1371/journal.pntd.000825 4

8. Bern C, Hightower AW, Chowdhury R, Ali M, Amann J,Wagatsuma Y, Haque R, Kurkjian K, Vaz LE, Begum M,Akter T, Cetre-Sossah CB, Ahluwalia IB, Dotson E, Secor WE, Breiman RF, Maguire J, 2005. Risk factors for kala-azar in Bangladesh. Emerg Infect Dis 11: 655-662.

9. Desjeux P, 1996. Leishmaniasis. Public health aspects and control. Clin Dermatol 14: 417-423.

10. Cerf BJ, Jones TC, Badaro R, Sampaio D, Teixeira R, Johnson WD, 1987. Malnutrition as a risk factor for severe visceral leishmaniasis. J Infect Dis 156: 1030-1033.

11. Boelaert M, Meheus F, Sanchez A, Singh SP, Vanlerberghe V, Picado A, Meessen B, Sundar S, 2009. The poorest of the poor: a poverty appraisal of households affected by visceral leishmaniasis in Bihar, India. Trop Med Int Health 14: 639-644. 
12. Harhay MO, Olliaro PL, Vaillant M, Chappuis F, Lima MA, Ritmeijer K, Costa $\mathrm{CH}$, Costa DL, Rijal S, Sundar S, Balasegaram M, 2011. Who is a typical patient with visceral leishmaniasis? Characterizing the demographic and nutritional profile of patients in Brazil, East Africa, and South Asia.Am J Trop Med Hyg 84: 543-550.

13. G. S. Bhunia, N. Chatterjee, V. Kumar, R. Mandal, P. Das, and S. Kesari, "Remote sensing and GIS: tools for the prediction of epidemic for the intervention measure," in Proceedings of the 14th Annual International Conference and Exhibition on Geospatial Information technology and Application, Gurgaon, India, February 2012, India Geospatial forum (PN-31).

14. S. Sudhakar, T. Srinivas, A. Palit, S. K. Kar, and S. K. Battacharya,"Mapping of risk prone areas of kala-azar (Visceral leishmaniasis) in parts of Bihar state, India: an RS and GIS approach," Journal of Vector Borne Diseases, vol. 43, no. 3, pp.115-122, 2006.

15. Gouri Sankar Bhunia, Shreekant Kesari, Nandini Chatterjee, Vijay Kumar, and Pradeep Das. The Burden of Visceral Leishmaniasis in India: Challenges in Using Remote Sensing and GIS to Understand and Control. Hindawi Publishing Corporation ISRN Infectious Diseases Volume 2013, Article ID $675846, \quad 14$ pageshttp://dx.doi.org/10.5402/2013/675846

16. Thakur CP, Meenakshi Thakur AK, Thakur S. Newer strategies for the kala-azar elimination programme in India. Indian $\mathbf{J}$ Med Res. 2009; 29: 102-4.

17. WHO-NVBDCP. Accelerated plan for kalaazar elimination 2017. Directorate National Vector Borne Disease Control Programme. 2017. Available from: https://www.who.int/leishmaniasis/resource s/Accelerated_plan_for_Kalaazar_Elimination_2017/en/

18. "District Dumka, Government of Jharkhand | The Land of Temples | India". Retrieved 30 December 2020.

19. Kumar R, Kumar P, Chowdhary RK, Pai K, Kumar K, Pandey HP, Singh VP, Sundar S, 1999. Kala-azar epidemic in Varanasi district, India. Bull World Health Organ 77: 371-374.

20. Rai R, Sehgal P, 1990. Kala-azar in Varanasi (U.P.): preliminary observations. J Commun Dis 22: 120-123.

21. Ranjan A, Sur D, Singh VP, Siddigue NA, Manna B, Lal CS, Sinha PK, Kishore K, Bhattacharya SK, 2005. Risk factors for Indian kala-azar. Am J Trop Med Hyg 73: 74-78.

22. Perry And Others Visceral Leishmaniasis Prevalence and Associated Risk Factors in the Saran District of Bihar, India, from 2009 to July of 2011 Am. J. Trop. Med. Hyg., 88(4), 2013, pp. 778-784 doi:10.4269/ajtmh.12-0442 Copyright (C) 2013 by The American Society of Tropical Medicine and Hygiene

23. Bern C, Courtenay O, Alvar J, 2010. Of cattle, sand flies and men: a systematic review of risk factor analysis for South Asian visceral leishmaniasis and implications for elimination. PLoS Negl Trop Dis 4: 1-9.

24. Thakur CP, 2000. Socio-economics of visceral leishmaniasis in Bihar (India). Trans R Soc Trop Med Hyg 94: 156-157.

25. Claborn DM, 2010. The biology and control of leishmaniasis vectors. J Glob Infect Dis 2: 127-134.

26. Ibrahim ME, Lambson B, Yousie AO, Deifalla NS, Alnaiem DA, Ismail A, Yousif H, Ghalib HW, Khalil EAG, Kadaro A, Barker DC, El Hassan AM, 1999. Kala-azar in a high transmission focus: an ethnic and geographic dimension. Am J TropMed Hyg 61: 941-944.

27. Kishore K, Kumar V, Kesari S, Dinesh DS, Kumar AJ, Das P,Bhattacharya SK, 2006. Vector control in leishmaniasis. Indian $\mathrm{J}$ Med Res 123: 467-472.

28. Killick-Kendrick R, 1999. The biology and control of phlebotomine sand flies. Clin Dermatol 17: 279-289.

How to cite this article: Vidushi Topno, Vikas Oraon. Assessment of kala-azar in Dumka district of Jharkhand, India. International Journal of Research and Review. 2022; 9(1): 305-311. DOI: https://doi.org/10.52403/ijrr. 20220136 